Research Article

\title{
An Experimental Study on the Deformation and Strength Characteristics of Q3 Loess under a Plain Strain Anisotropic Consolidation Condition
}

\author{
Yu Zhang $\mathbb{D}^{1,2}$ Yang Zhao, ${ }^{1}$ Jin Liu, ${ }^{1}$ Tian-Yi Meng, ${ }^{1}$ Sheng-Jun Shao $\mathbb{D}^{2,3}$ \\ and Fang-Tao She ${ }^{2,3}$ \\ ${ }^{1}$ Civil and Architecture Engineering, Xi'an Technological University, Xi'an, Shaanxi 710021, China \\ ${ }^{2}$ Shaanxi Key Laboratory of Loess Mechanics and Engineering, Xi'an University of Technology, Xi'an, Shaanxi 710048, China \\ ${ }^{3}$ Institute of Geotechnical Engineering, Xi'an University of Technology, Xi'an, Shaanxi 710048, China \\ Correspondence should be addressed to Sheng-Jun Shao; 327388440@qq.com
}

Received 10 June 2020; Revised 13 January 2021; Accepted 18 January 2021; Published 2 February 2021

Academic Editor: Valeria Vignali

Copyright (C) $2021 \mathrm{Yu}$ Zhang et al. This is an open access article distributed under the Creative Commons Attribution License, which permits unrestricted use, distribution, and reproduction in any medium, provided the original work is properly cited.

To study the strength, deformation characteristics, and intermediate principal stress of intact loess, vertical loading stress tests with different initial stress state $k$ value were conducted under different confining pressures. Plane strain tests were carried out by the transformed true triaxial apparatus of Xi'an University of Technology. The study shows that loess tends to be in a plastic failure state in different confining pressures and $k$ values, and the stress-strain relationship curve is of a hardening type. Results reveal that loess lateral and volume deformations have nonlinear relationships with its vertical deformation, and volume deformation shrinks in the process of shearing. The effect of confining pressure on soil deformation is greater than $k$ value. The intermediate principal stress coefficient decreases with the increase of the confining pressure and transforms from increasing to decreasing with the increase of $k$ value (ranging from 0.2 to 0.4 ). In brief, the loess failure strength is closely related to $k$ value, confining stress, and spherical stress state. When $k$ value increases, cohesion effect reduces, whereas internal friction angle increases linearly. The influence of $k$ value on soil strength and deformation is closely related to confining pressure.

\section{Introduction}

The distribution area of loess is approximately $75.8 \%$ of the total land area in northwestern China, where Q3 loess (also known as "Malan Loess") accounts for approximately $75.8 \%$ [1]. Assessing the real stress and deformation character of loess could help us understand the strength and reduce cost. Previous studies usually examined loess characteristics by conventional triaxial test under the isotropic consolidation [2-8] and revealed the strength and deformation behaviors. However, the conventional triaxial test neglects the contribution of intermediate principal stress to loess strength [9-11], which is inconsistent with the soil stress state in the practical projects. Engineering projects, such as deep foundation pit, retaining wall, highway embankment, dam, and tunnel, could be approximated as a plane strain status. Research on soil strength under plane strain state is still mainly focused on theoretical analysis and mathematical derivation under an isotropic consolidation state [12-14]. Related studies have been carried out on sand, soft soil, and unsaturated soil [15-17] but were rarely conducted on intact loess.

Isotropic consolidation could not display the real stress state and path in engineering practice. The anisotropic consolidation ( $k$ value consolidation, $k=\sigma_{1} / \sigma_{3}$ ) state can simulate various initial stress states of loess, such as high-filled roadbed, airport engineering, and foundation pits. The soft soil strength on the plane strain state with anisotropic consolidation studies indicates that the initial stress state greatly influences strength [18]. The 
strength and deformation characteristics of intact loess have been discussed under a plane strain isotropic consolidation state without considering the effect of initial stress state [19-21].

Therefore, carrying out a comprehensive analysis of the strength, deformation characteristics, and intermediate stress state of intact loess by plane strain test under anisotropic consolidation states is of great importance. In this study, the true triaxial apparatus of Xi'an University of Technology was transformed to perform the plain strain test of intact loess under anisotropic consolidation states. The results could help understand the loess mechanical properties in engineering practice.

\section{Materials and Experimental Procedures}

All the mechanical tests mentioned in this study were conducted under plane strain conditions. First, the mechanical symbols used in this study are defined, and their transformational relations are given as follows:

(i) $\sigma_{1}$ : maximum axial stress (maximum principal stress)

(ii) $\sigma_{2}$ : intermediate principal stress

(iii) $\sigma_{3}$ : confining stress

(iv) $\mathrm{p}$ : mean stress

(v) q: general shear stress

(vi) b: intermediate principal stress coefficient

(vii) $\varepsilon_{1}$ : axial strain (vertical strain)

(viii) $\varepsilon_{3}$ : lateral strain

(xi) $\varepsilon_{v}$ : volumetric strain

(x) $\mathrm{k}$ : anisotropic consolidation state

$$
\begin{aligned}
p & =\frac{\sigma_{1}+\sigma_{2}+\sigma_{3}}{3}, \\
q & =\frac{1}{\sqrt{2}}\left[\left(\sigma_{1}-\sigma_{2}\right)^{2}+\left(\sigma_{2}-\sigma_{3}\right)^{2}+\left(\sigma_{3}-\sigma_{1}\right)^{2}\right]^{(1 / 2)}, \\
\varepsilon_{v} & =\varepsilon_{1}+\varepsilon_{2}+\varepsilon_{3}, \\
b & =\frac{\sigma_{1}-\sigma_{3}}{\sigma_{2}-\sigma_{3}}, \\
k & =\frac{\sigma_{1}}{\sigma_{3}} .
\end{aligned}
$$

2.1. Specimen Preparation. The intact loess samples deposited in late Pleistocene (Q3) were obtained from the steep ridge of Xi'an Bailu Tableland with the depth of 6-8.0 m, following the standard method of the geotechnical test. The soil is yellow-brown silty clay with occasional nodules, a silt sand group, and insect holes. To ensure the uniformity of soil moisture content, the section was dug $1 \mathrm{~m}$ into fresh soil. The soil was cut into a rectangular block, wrapped by black plastic film, and taped to avoid moisture dissipation. The intact loess samples were cut to $7 \mathrm{~cm} \times 7 \mathrm{~cm} \times 14 \mathrm{~cm}$ carefully by a sample machine to minimize disturbance.

The specimens had a dry density of $1.46 \mathrm{~g} / \mathrm{cm}^{3}$, a natural water content of $15.8 \%$, a liquid limit of $32.82 \%$, a plastic limit of $21.58 \%$, a plastic index of 11.24 , and a specific gravity of 2.7 .

2.2. Upgrading the True Triaxial Apparatus. The true triaxial apparatus (Figure 1(a)), developed by the Institution of Geotechnical Engineering, Xi'an University of Technology [7], was upgraded for the plane strain test. Two smooth rigid plates (Figure 1(b)) embedded with the Earth pressure cells (Figure 1(c)) were placed in the $\sigma_{2}$ direction of the pressure chamber to measure the stress variations during the shearing process.

Lateral minor principal stress was loaded by water capsule, and vertical maximum principal stress was loaded by vertical loading jack. The confining pressure values were controlled by the control system of the equipment.

2.3. Experimental Procedures. For each confining pressure (50,100,150, and $200 \mathrm{kPa})$, four samples with different $k$ values $(1,1.25,1.5$, and 2$)$ were prepared; 16 samples were prepared. These samples were consolidated by the apparatus for 6 hours under draining conditions.

After consolidation, the vertical loading was applied with the constant lateral confining pressure until the vertical strain reached $12 \%$. During this stage, sample deformation and stress changes in different directions were measured. The frequency of data acquisition is 5 seconds.

\section{Experimental Results and Discussion}

3.1. Stress Path with Different $k$ Values. The stress path with different $k$ values is shown in Figure 2 . When $k=1$, it is isotopic consolidation, and the difference between major principal stress and minor principal stress starts from 0 . When $k=1,1.25,1.5$, and 2 , the differences start over 0 . With the increase of $k$ value, the initial difference also increases. In the same $k$ value condition, high consolidation confining pressure makes a great difference.

3.2. Stress-Strain Relationship. The intact loess has original structural strength. The stress-strain curve varies with different origins, dates, and stresses, generally divided into three types and five kinds of forms, namely, the brittle failure type (strong softening and weak softening), plastic damage (strong hardening and weak hardening), and ideal plastic type [1].

In Figure 3, during the shearing process, the stress-strain curves with different $k$ values or confining pressures are of the hardening type. In all of these conditions, the difference between major principal stress and minor principal stress increases with vertical strain and belongs to the hyperbolic type. In the same $k$ value condition, high consolidation confining pressure makes a great difference between major 


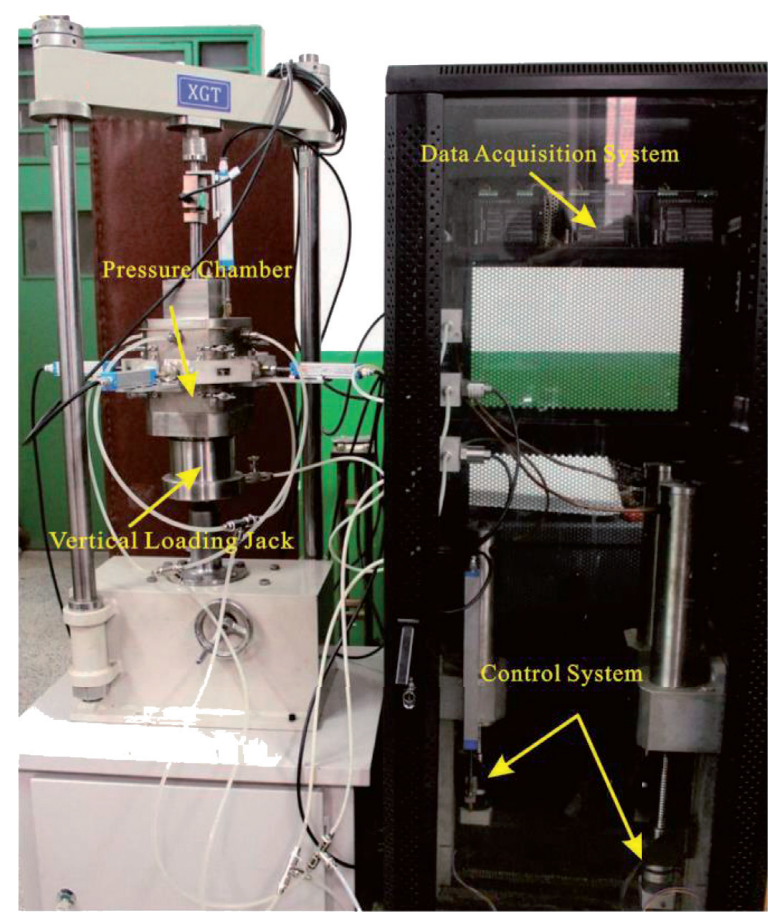

(a)

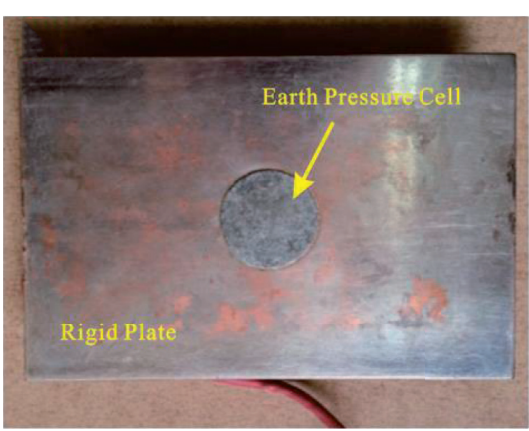

(b)

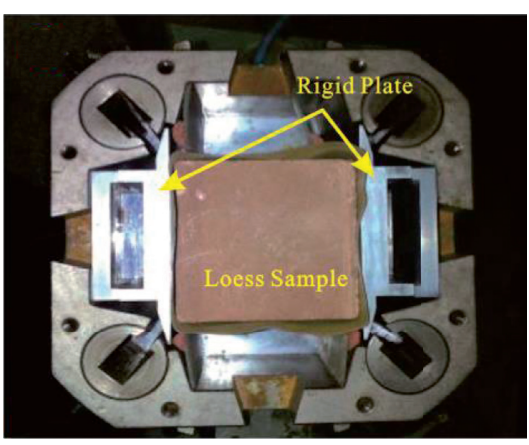

(c)

FIGURE 1: Upgraded XGT true triaxial apparatus: (a) true triaxial system, (b) smooth rigid plates embedded with the Earth pressure cells, and (c) the sample loading in the pressure chamber, which is laterally confined by b and a water capsule.

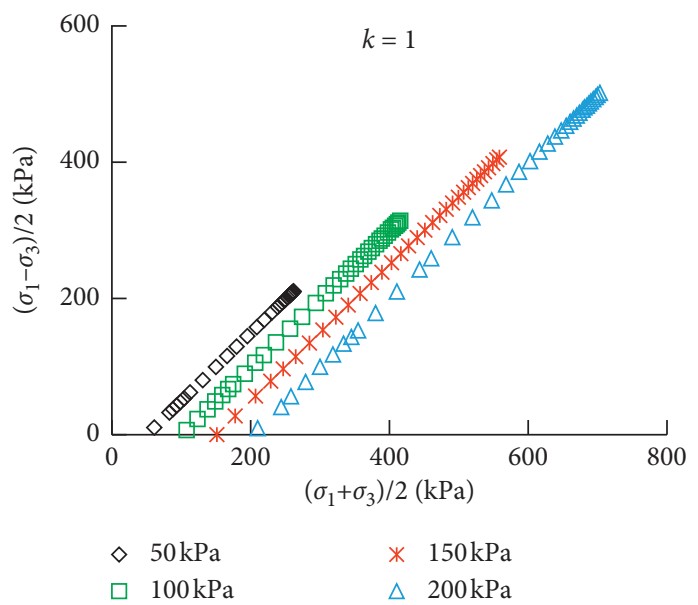

(a)

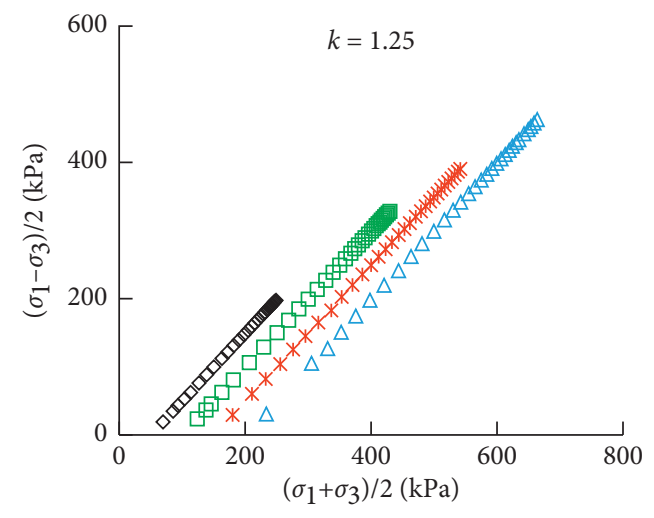
$\diamond 50 \mathrm{kPa}$
* $150 \mathrm{kPa}$
$\square 100 \mathrm{kPa}$
$\triangle 200 \mathrm{kPa}$

Figure 2: Continued. 


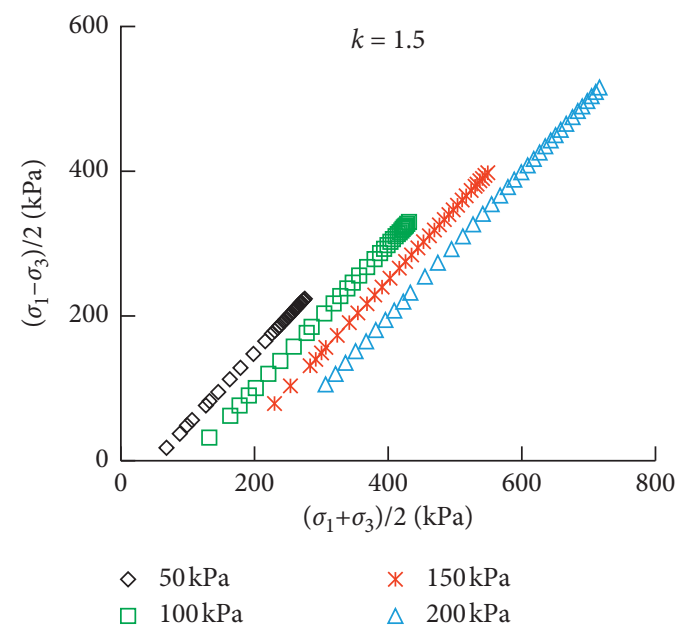

(c)

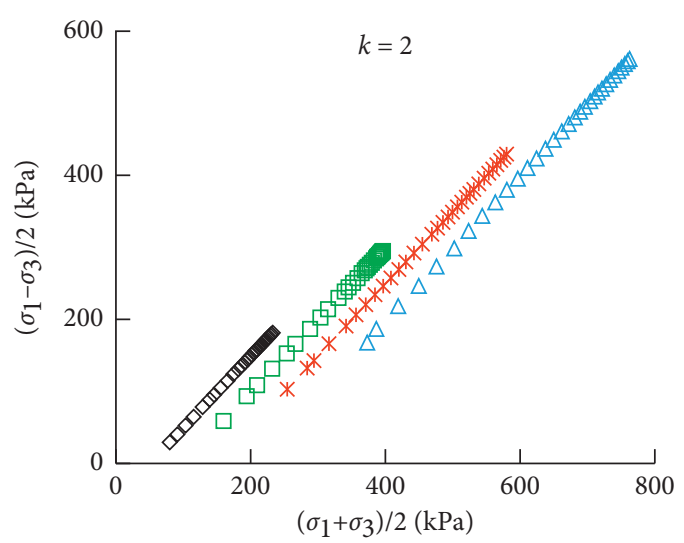
$\diamond 50 \mathrm{kPa}$
* $150 \mathrm{kPa}$
$\square 100 \mathrm{kPa}$
$\triangle 200 \mathrm{kPa}$

(d)

Figure 2: Stress path of vertical loading.

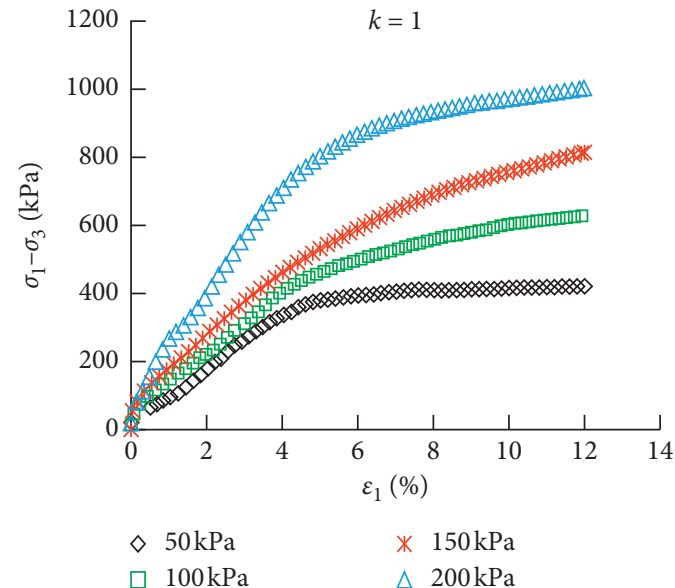

(a)

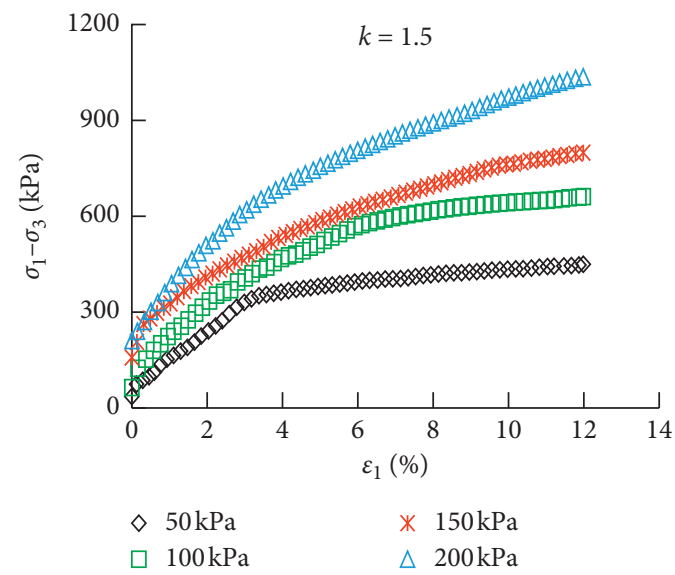

(c)

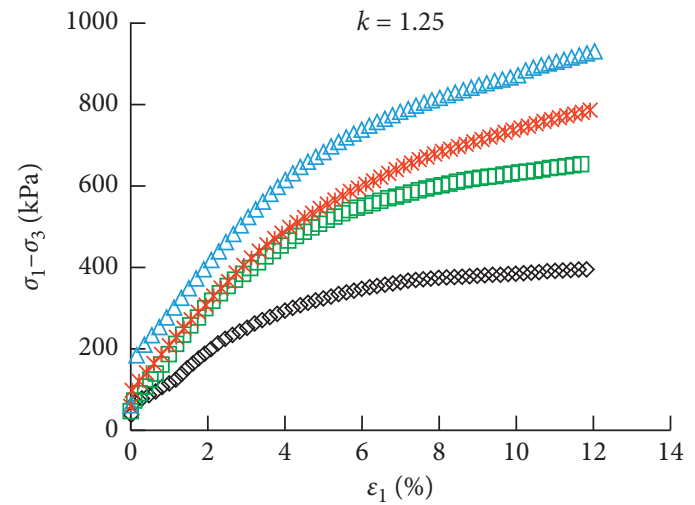
$\diamond 50 \mathrm{kPa}$
* $150 \mathrm{kPa}$

$\square 100 \mathrm{kPa}$

(b)

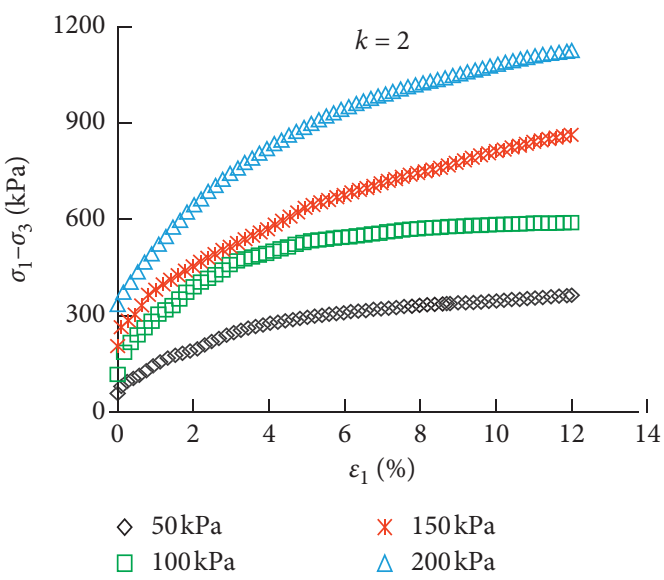

(d)

FIgURE 3: Stress-strain curves of intact loess at different $k$ values. 


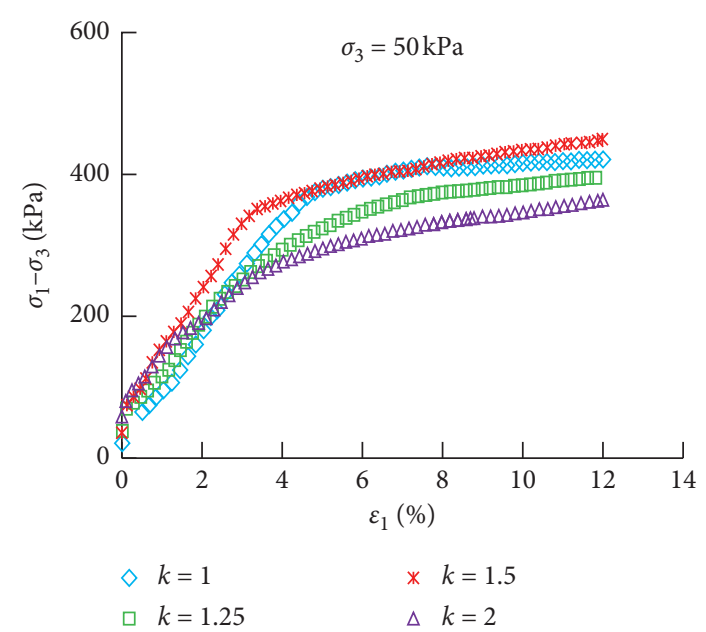

(a)

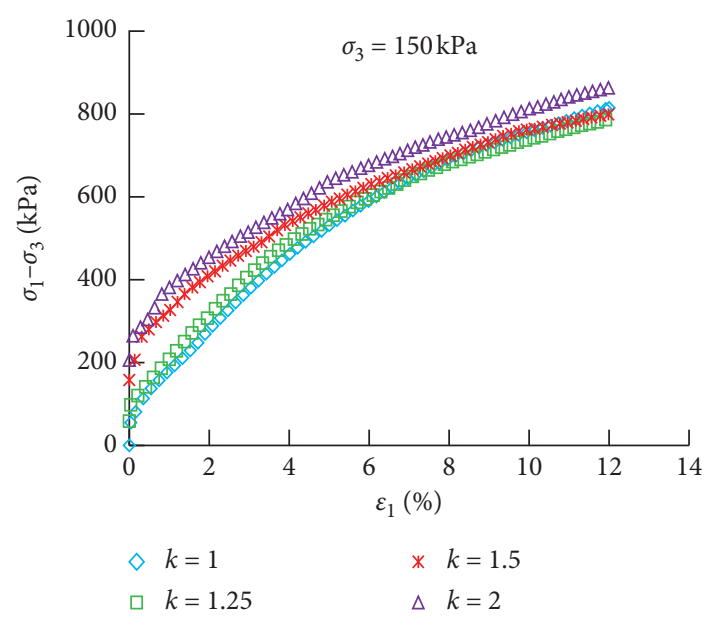

(c)

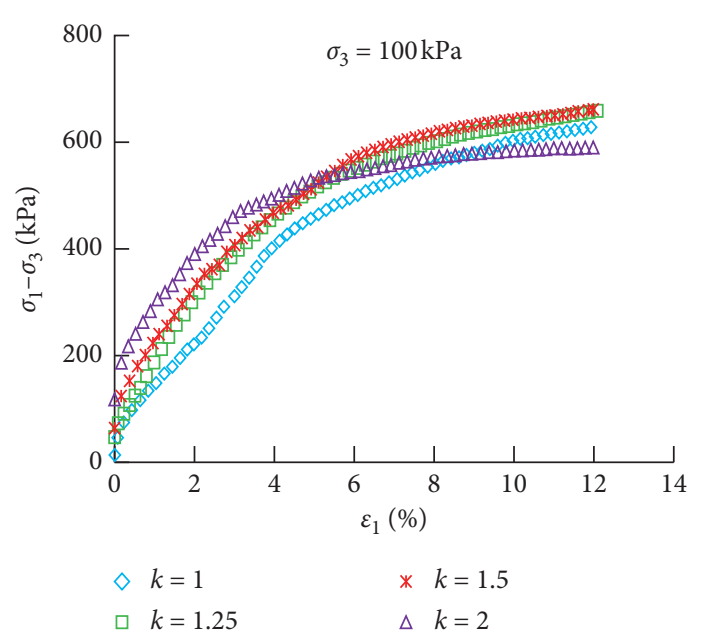

(b)

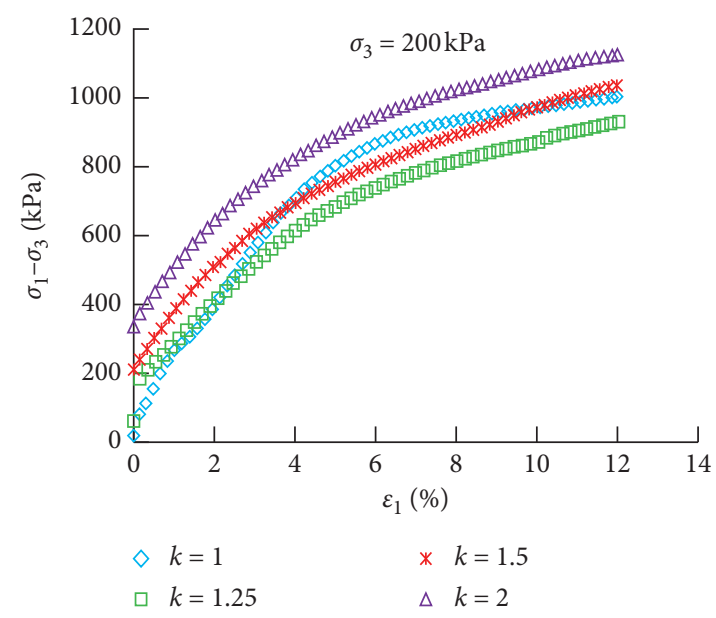

(d)

FiguRE 4: Stress-strain curves of intact loess at different confining pressures.

principal stress and minor principal stress and high initial tangent modulus.

Figure 4 shows the stress-strain curves on each confining pressure $(50,100,150$, and $200 \mathrm{kPa})$. With each certain confining pressure, the different $k$ values have no significant influence on the difference between major principal stress and minor principal stress. However, when the confining pressure is low, high $k$ value shows a low difference between major principal stress and minor principal stress. With the increase of confining pressure, high $k$ value indicates a great difference between major principal stress and minor principal stress.

The different initial consolidation degree $k$ values that influence the strength of intact loess are related to the confining pressure. Given the original structural strength of loess, when the confining pressure is small, the $k$ value is also small under the condition of consolidation. Therefore, the vertical fissure of intact loess becomes small, and soil particles are compacted, which could improve the loess shear capacity and enhance the loess strength. With the increase of $k$ value, the original structure of loess is destroyed. However, because the secondary structure has not yet been formed because of the low confining pressure, the strength of intact loess is weakened to some extent. Therefore, under the small consolidation confining pressure, the greater the $k$ value, the higher the stress-strain curve; the stress-strain curve is low when $k$ value is high. With the increase of confining pressure, the original loess structure is destroyed, and the secondary structure is gradually formed. The secondary structural strength increased more than the damaging effect on the strength of the original structure. Thus, the increase of the $k$ value could further help loess compaction. Therefore, as shown in the stress-strain curve, the greater the $k$ value is, the higher the stress-strain curve is and the greater the soil strength becomes.

The plastic failure of loess has different confining pressures in the vertical loading condition. Consolidation confining pressure and initial stress state $k$ values affect the 


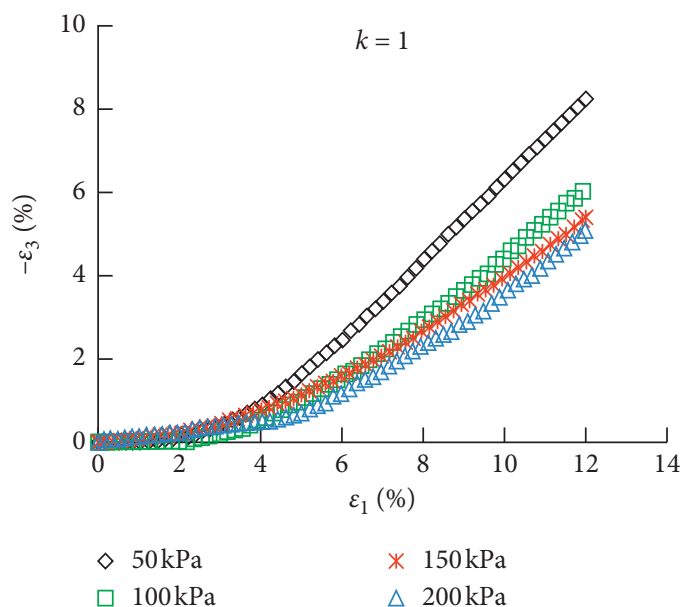

(a)

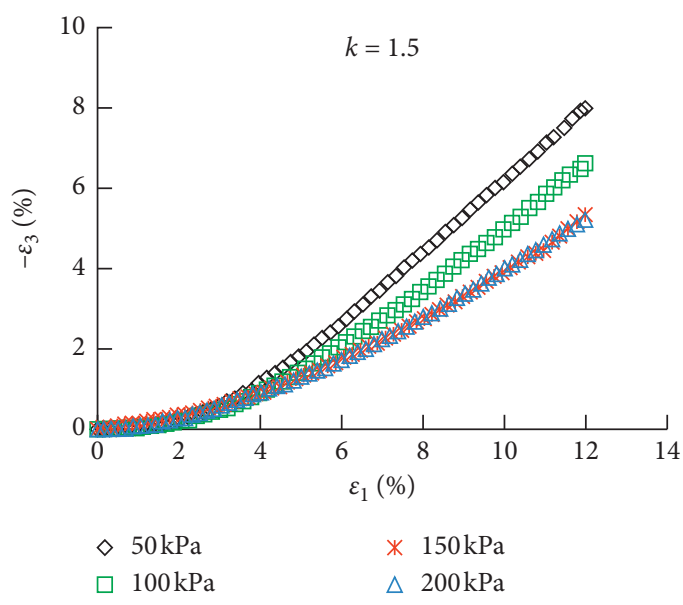

(c)

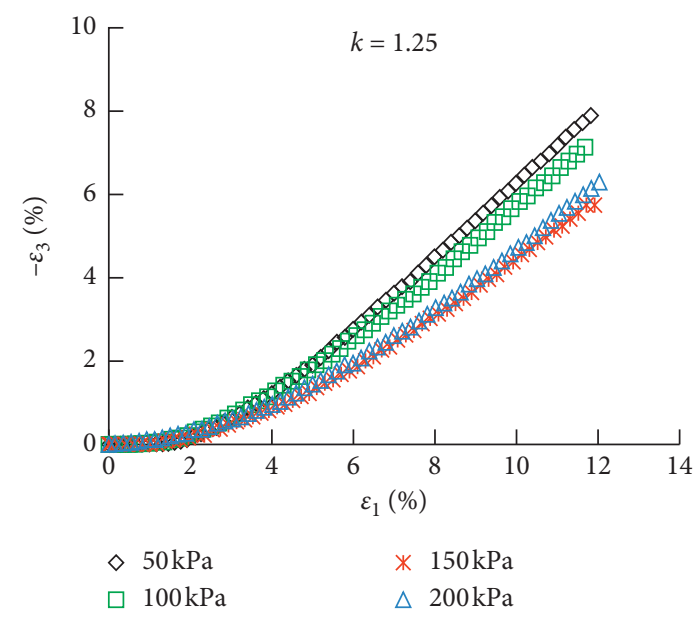

(b)

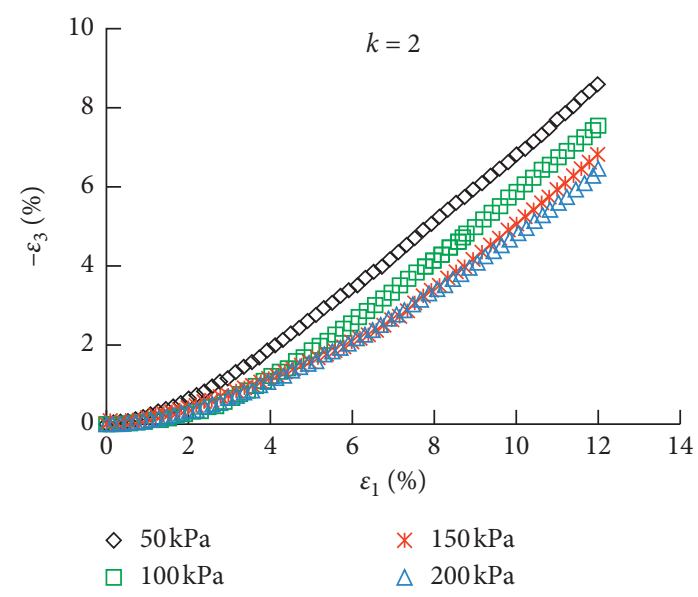

(d)

FIgURE 5: Lateral strain-vertical strain curves of intact loess at different $k$ values.

soil strength characteristics. The influence of the $k$ value with different initial stress states on the strength of loess is closely related to the magnitude of consolidation stress.

3.3. Lateral Deformation Characteristics. The relationships between the lateral strain $\left(-\varepsilon_{3}\right)$ and the vertical strain $\left(\varepsilon_{1}\right)$ are shown in Figure 5. At the beginning of the shearing process, all of these conditions with different $k$ values or confining pressures show a small $-\varepsilon_{3}$ value. When $\varepsilon_{1}$ is raised to $2 \%-4 \%$, the plastic strain is developed, the loess structure begins to yield, and $-\varepsilon_{3}$ is developed significantly. With each certain $k$ value, the enhanced consolidation confining pressure makes low $-\varepsilon_{3}$. Besides, when the confining pressure is $50 \mathrm{kPa}$, the $k$ values have no significant influence on $-\varepsilon_{3}$. With increased confining pressure, high $k$ value makes high $-\varepsilon_{3}$, although the trend is unclear. Overall, the enhanced consolidation confining pressure restricts the lateral deformation significantly. Besides, the effect of different initial stress state $k$ values on lateral deformation is significantly relevant with consolidation confining pressure.
3.4. Volume Strain Characteristics of Intact Loess. The relationships between the volume strain $\left(\varepsilon_{v}\right)$ and vertical strain $\left(\varepsilon_{1}\right)$ under different $k$ values and confining pressures are shown in Figure 6.

With each certain $k$ value, increased consolidation confining pressure enhances the volume strain $\left(\varepsilon_{v}\right)$. When the confining pressure is $50 \mathrm{kPa}$, high $k$ value makes high $\varepsilon_{v}$. However, when the confining pressure is 100, 150, and $200 \mathrm{kPa}$, high $k$ value makes low $\varepsilon_{v}$.

The analysis of Figure 6 reveals that the intact loess is characterized by shear shrinkage in a different initial stress state during vertical loading shearing. The regularity is obvious, and the relationships between volume and vertical strains are nonlinear. The increase of consolidation confining pressure limits the development of soil lateral deformation and enlarges the volume strain. With the increase of the initial stress state of $k$ value, the soil structure experiences are from enhancement to the damage process. When $k$ value is small, the initial structure is not destroyed, soil deformation is dominated by vertical compression, lateral deformation is not developed, and volume strain is increased. The increase of $k$ value damages the soil structure 


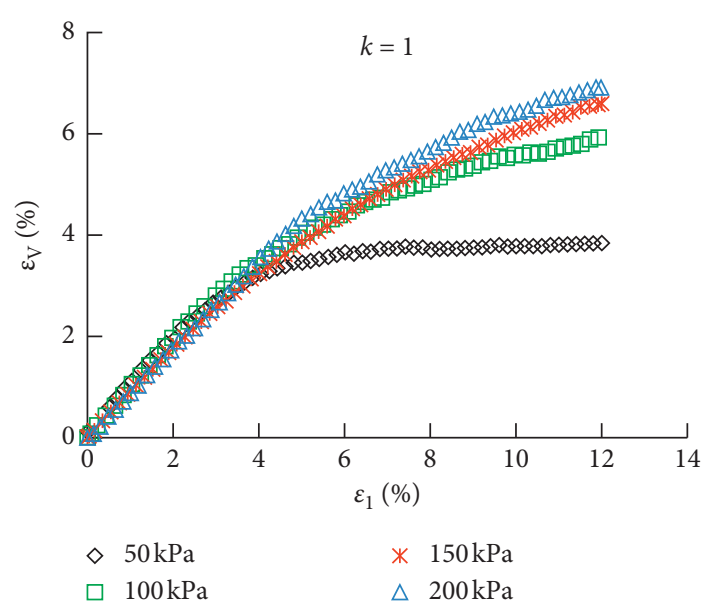

(a)

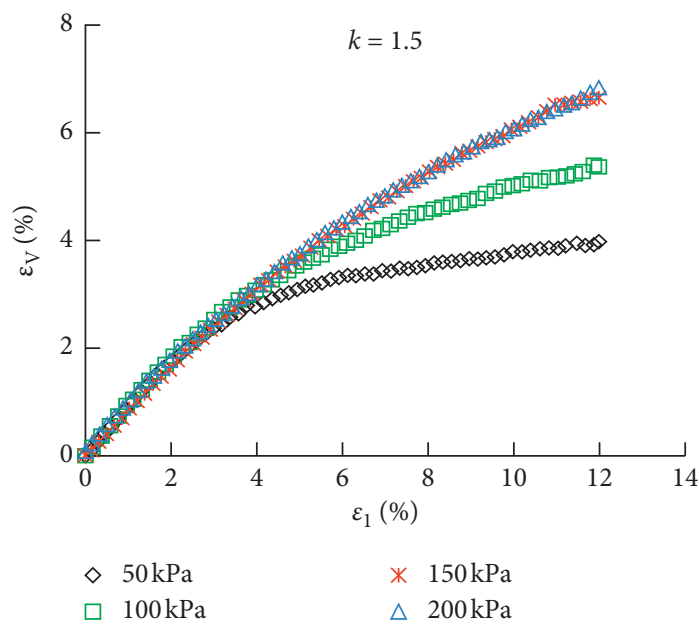

(c)

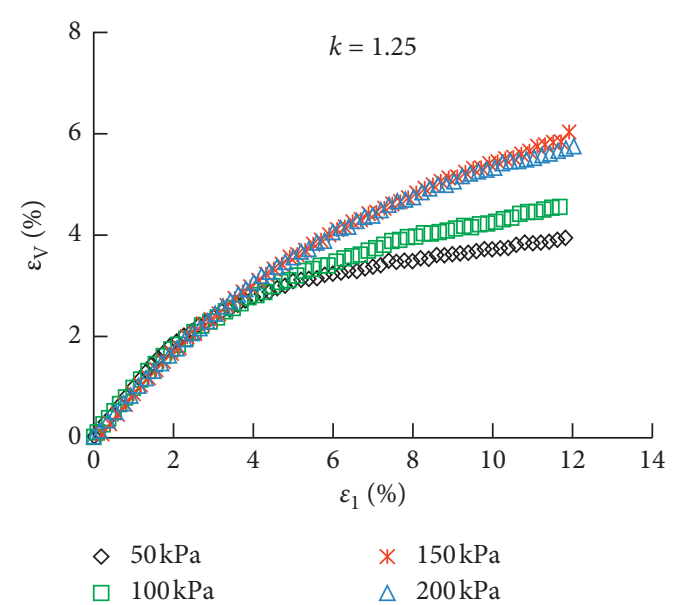

(b)

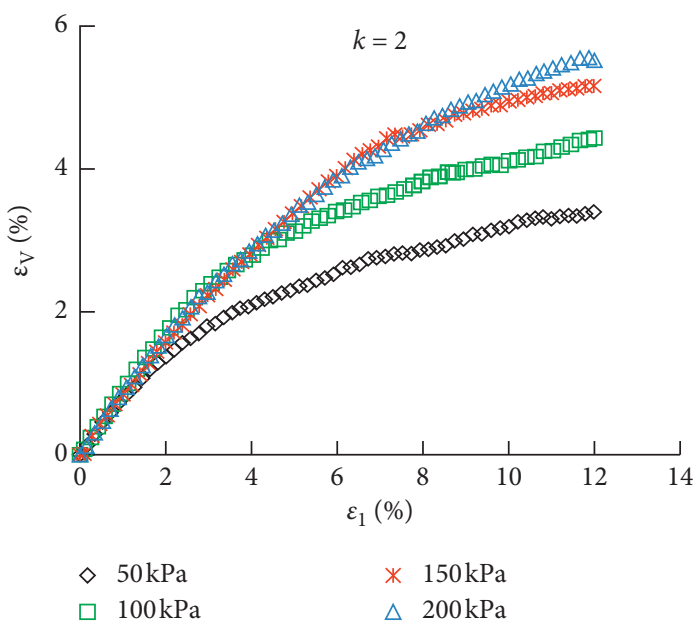

(d)

FIgURE 6: $\varepsilon_{v} \sim \varepsilon_{1}$ curves of intact loess at different confining pressures.

in the shear process, and lateral expansion deformation increases with the development of vertical compression deformation caused by the volume strain reduction.

3.5. Principal Stress Characteristics in the Plane Strain Direction. The state of intermediate principal stress in the plane strain direction directly determines the strength and deformation characteristics of soil under plane strain condition. It is also the primary reason for soil strength under a plane strain condition greater than the axisymmetric stress condition. Therefore, studying the evolution law of principal stress on plane strain direction is of great importance for revealing the strength and deformation characteristics of soil under plane strain condition.

The relationships of intermediate principal stress $\left(\sigma_{2}\right)$ and vertical strain $\left(\varepsilon_{1}\right)$ under different confining pressures and $k$ values are shown in Figures 7 and 8 .

When $k$ value is constant, $\sigma_{2}$ increases with the increase of confining pressure. When $k=1, \sigma_{2}$ starts to increase after the strain reaches a certain stage. It indicates that the structural strength of intact loess resists the external loading at the beginning of shearing. Therefore, no deformation is observed in $\sigma_{2}$ and $\sigma_{3}$ directions. This assumption is verified by the lateral deformation test. When $k$ value is bigger than $1, \sigma_{2}$ starts to increase at the beginning. Moreover, when $k$ value increases from 1 to $2, \sigma_{2}$ is enhanced greatly. When $k$ value increases from 1 to 1.5 , soil strength is improved, and the principal stress plays an important role. When $k$ value increases to 2 , the soil original structure is destroyed, and the secondary structure is gradually formed. During the earlier shearing stage, the initial structural damage is rapid, and the intermediate principal stress is small. With the development of the shearing process, the strength of the secondary structure and the intermediate principal stress increase rapidly. Figure 7 shows that the damage of soil strength in uneven consolidation when $k=2$ is greater than that of $k=1.5$. Thus, the intermediate principal stress of $k=2$ under different consolidation confining pressures is less than $k=1.5$. However, when confining pressure is constant, no clear regularity is shown with increased $k$ value. 


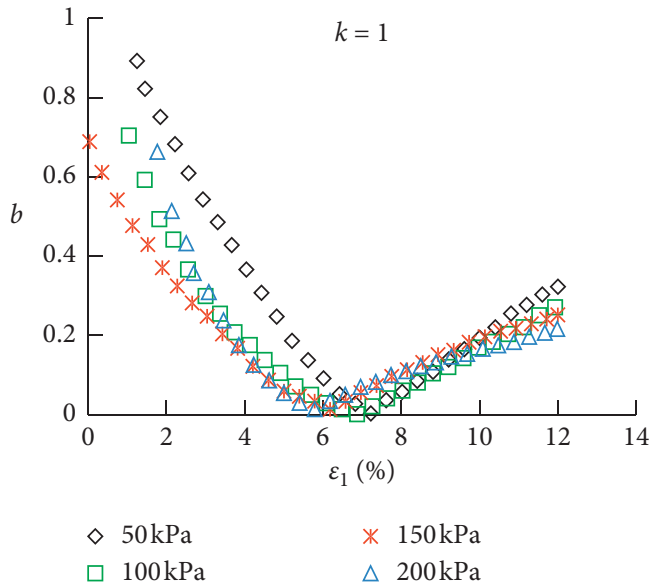

(a)

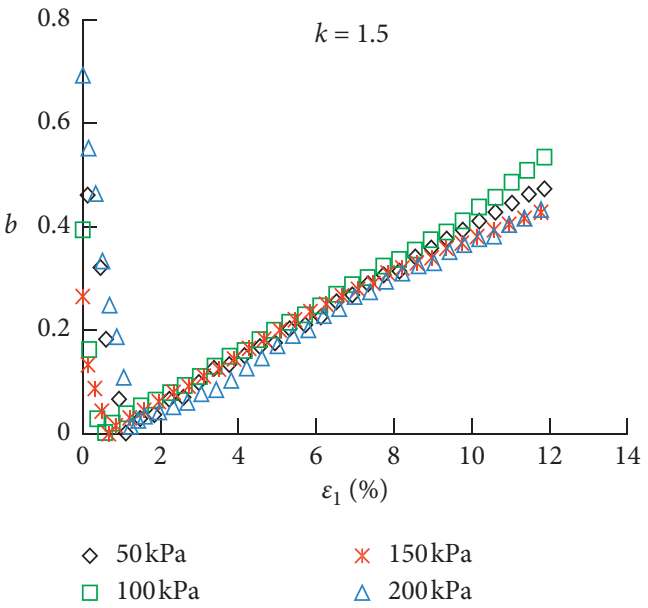

(c)

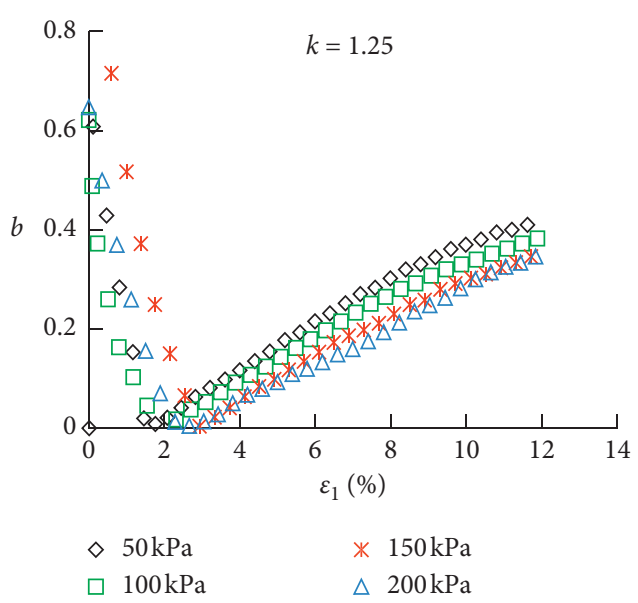

(b)

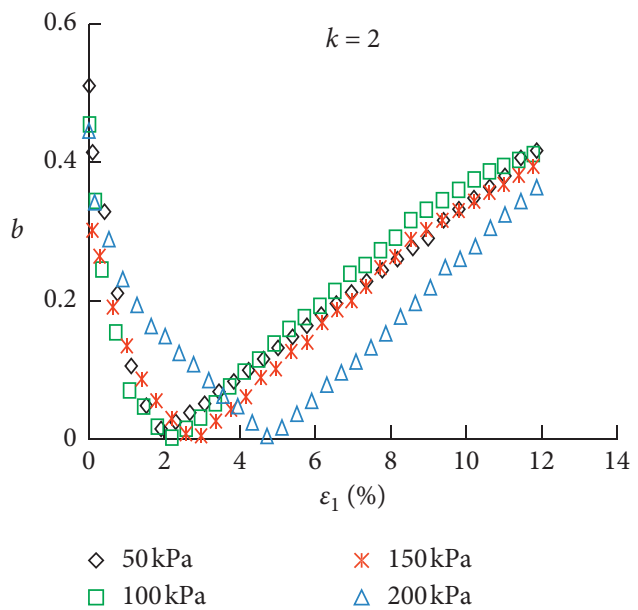

(d)

FIGURE 7: $b \sim \varepsilon_{1}$ curves of intact loess at different confining pressures.

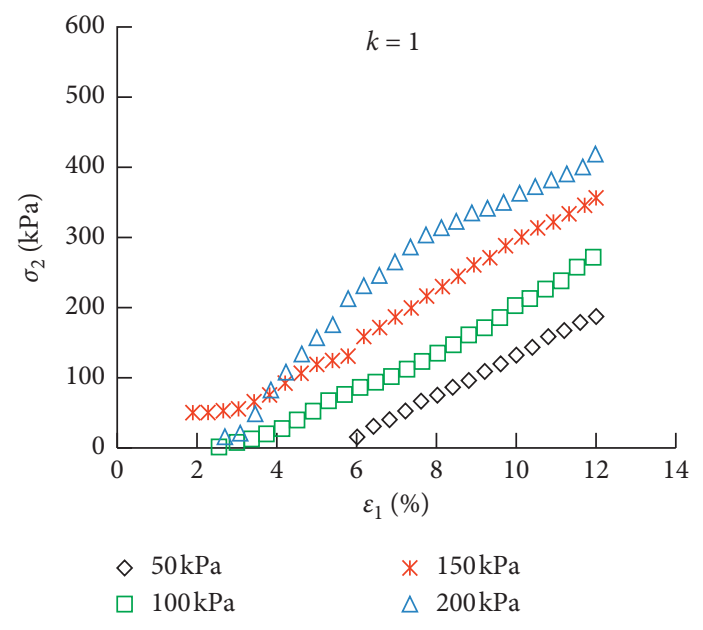

(a)

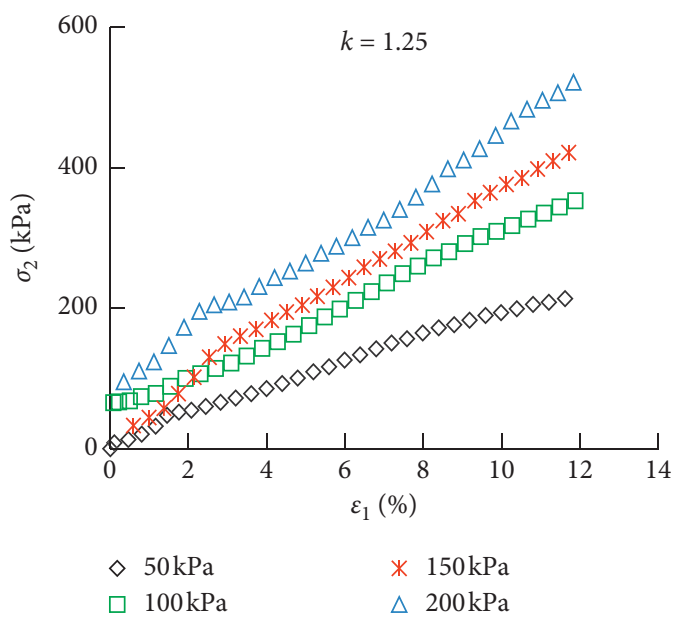

(b)

Figure 8: Continued. 


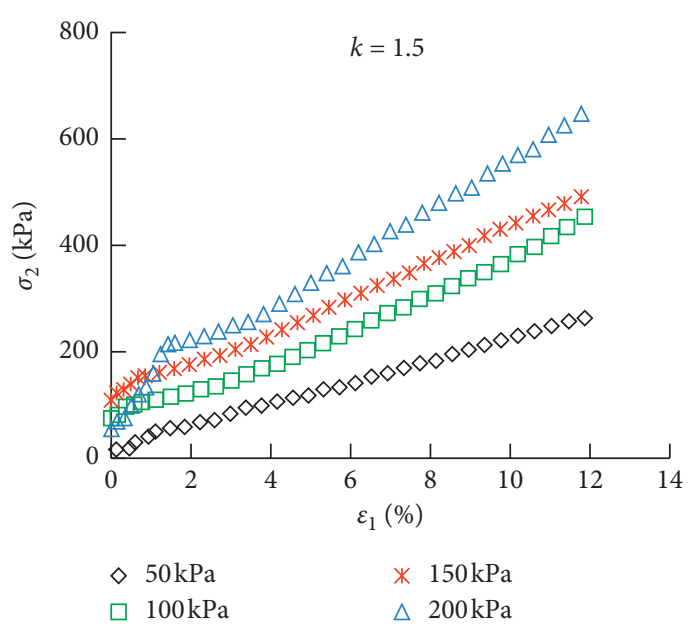

(c)

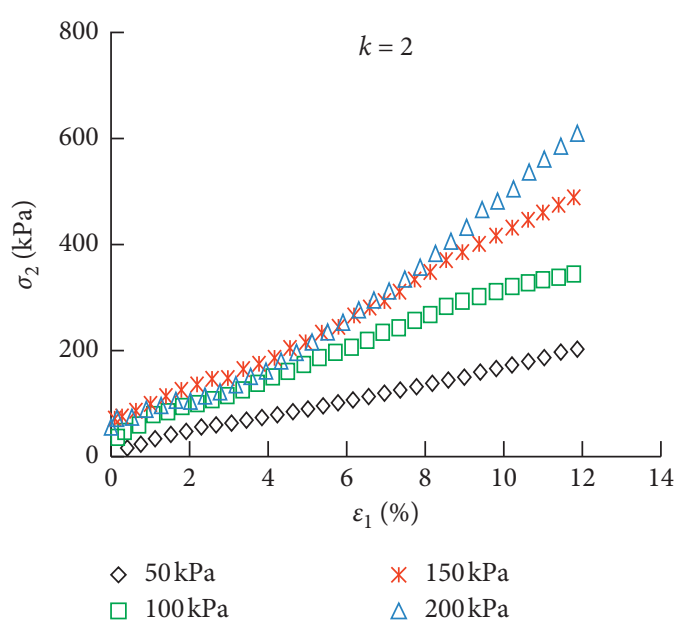

(d)

FIGURE 8: $\sigma_{2} \sim \varepsilon_{1}$ curves of intact loess at different confining pressures.

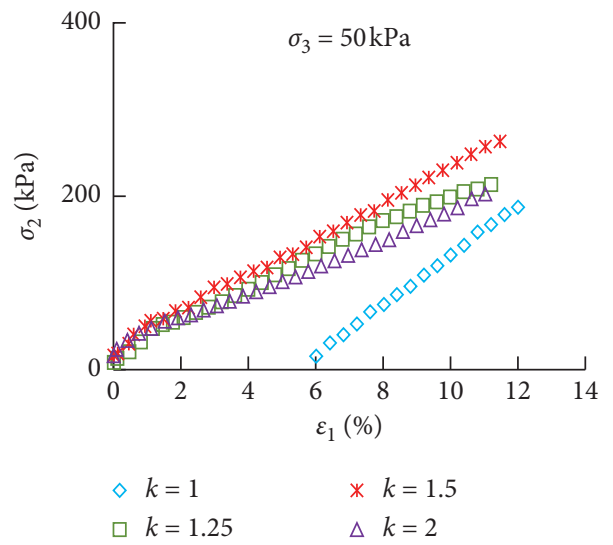

(a)

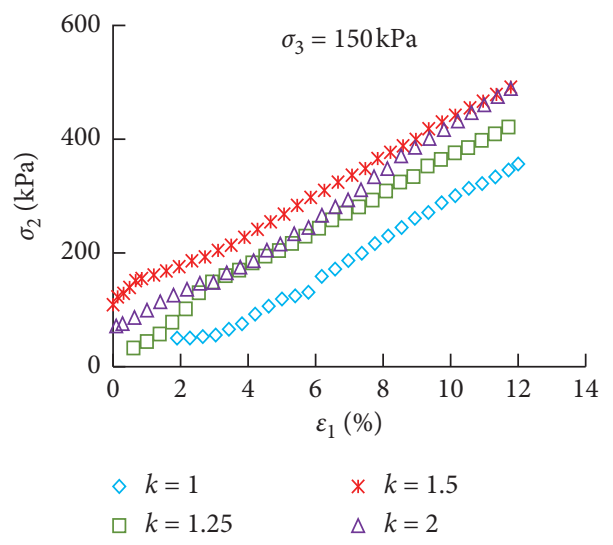

(c)

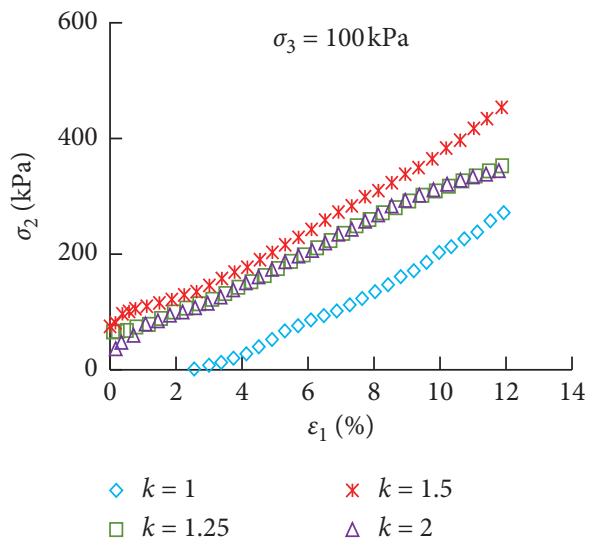

(b)

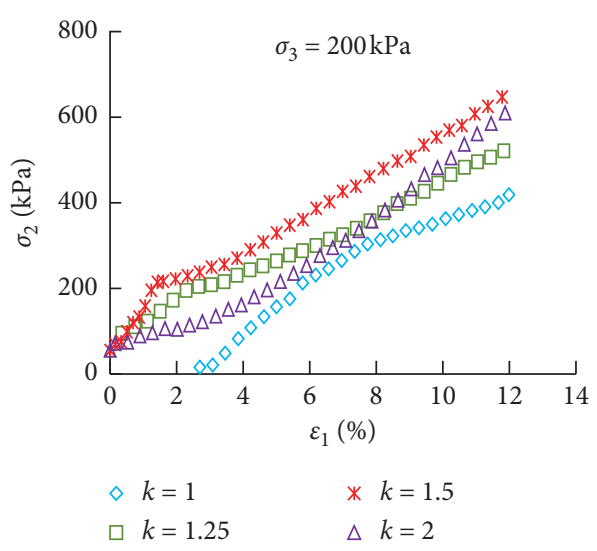

(d)

FIgURE 9: $\sigma_{2} \sim \varepsilon_{1}$ curves of intact loess at different $k$ values.

3.6. Intermediate Principal Stress Coefficient. The relationships between the intermediate principal stress coefficient $(b)$ and the vertical strain $\left(\varepsilon_{1}\right)$ are shown in Figures 9 and 10 .
From Figure 7, the intermediate principal stress coefficient decreases first and then increases, although different confining pressures and $k$ values exist. Given that the principal stress in the plane strain direction is small at 


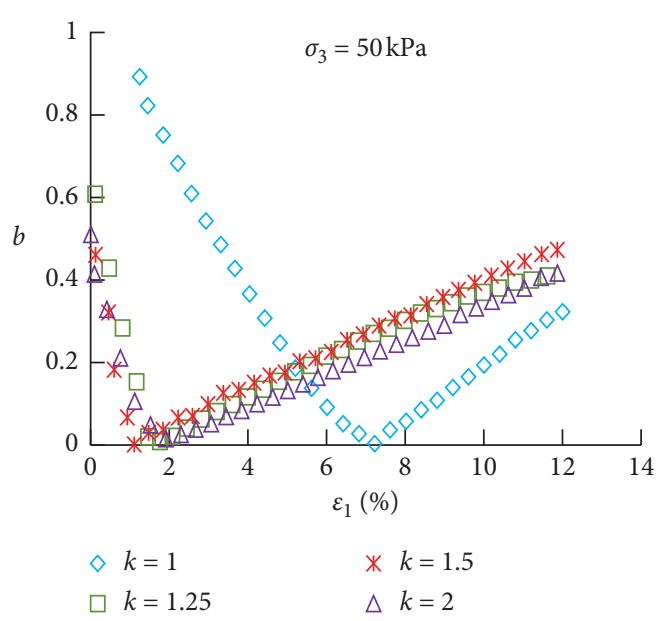

(a)

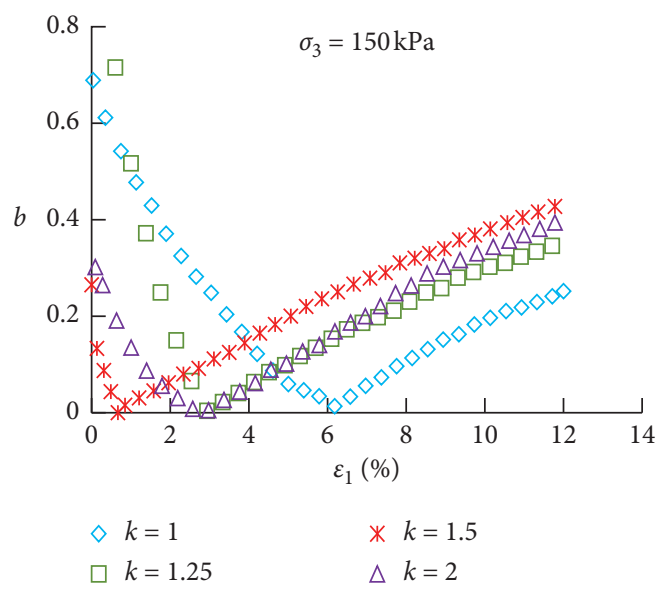

(c)

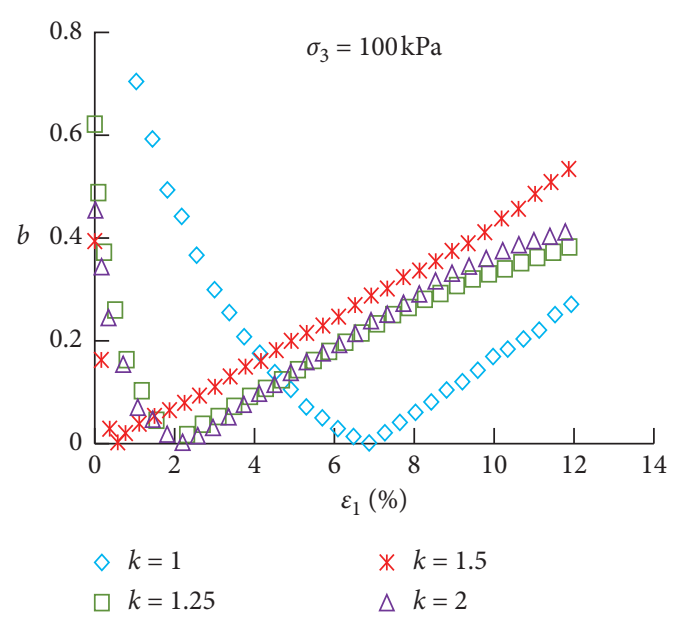

(b)

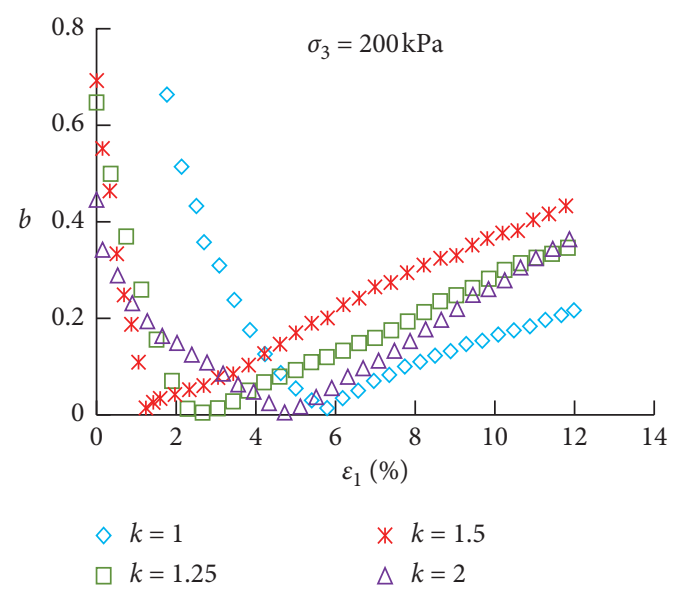

(d)

FIgURE 10: $b \sim \varepsilon_{1}$ curves of intact loess at different $k$ values.

the initial shear stage and gradually changes to the medium with the development of the shearing process, the relationship curve of $b \sim \varepsilon_{1}$ decreases first and then increases. In the shearing process, the time of soil in the plane strain state is related to the consolidation pressure and $k$ value. When $k$ value increases from 1 to 1.5 , the soil becomes more compacted with the increase of $k$ value and is earlier found in a plane strain state. When $k=2$, given the damage of soil structure, the plane strain state is later than $k=1.5$.

\section{Analysis of Failure and Strength Characteristics}

4.1. Analysis of the Failure Intermediate Principal Stress. Given the relationship between the failure intermediate principal stress and consolidation confining pressure, $k$ value is shown in Figures 11 and 12.

From Figures 11 and 12, the intermediate principal stress in a failure state increases with the enhancement of consolidation confining pressure with regularity. The greater the consolidation confining pressure, the higher the growth of intermediate principal stress. With the increase of the different initial stress states' $k$ value, the intermediate principal stress of failure increases first and then decreases with consistent regularity.

4.2. Analysis of the Failure Intermediate Principal Stress Coefficient. In a failure state, the relationship of $b_{f} \sim k$ is shown in Figure 13, and the relationship of $b_{f} \sim \sigma_{3 c}$ is shown in Figure 14.

Figures 13 and 14 show that the consolidation confining pressures and $k$ values affect the intermediate principal stress coefficient in the failure state. With the increase of consolidation confining pressure, the intermediate principal stress coefficient gradually decreases. With the increase of $k$ value, the intermediate principal stress coefficient increases first and then decreases, and the regularity is obvious. Under the plane strain condition, the intermediate principal stress coefficient $b_{f}$ of intact loess with different initial stress states is between 0.2 and 0.4 , which is slightly larger than that of isotropic consolidation from 0.15 to 0.35 . 


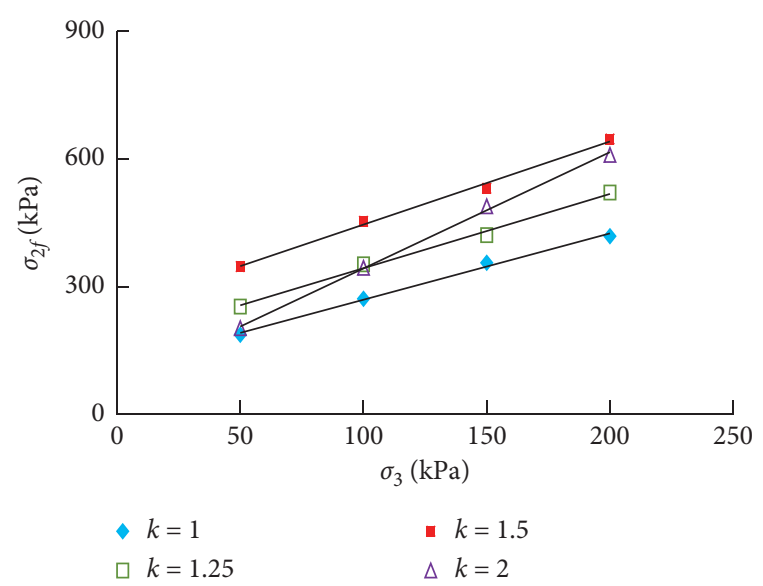

Figure 11: Change law between $\sigma_{2 f}$ and $\sigma_{3 c}$ in a failure state.

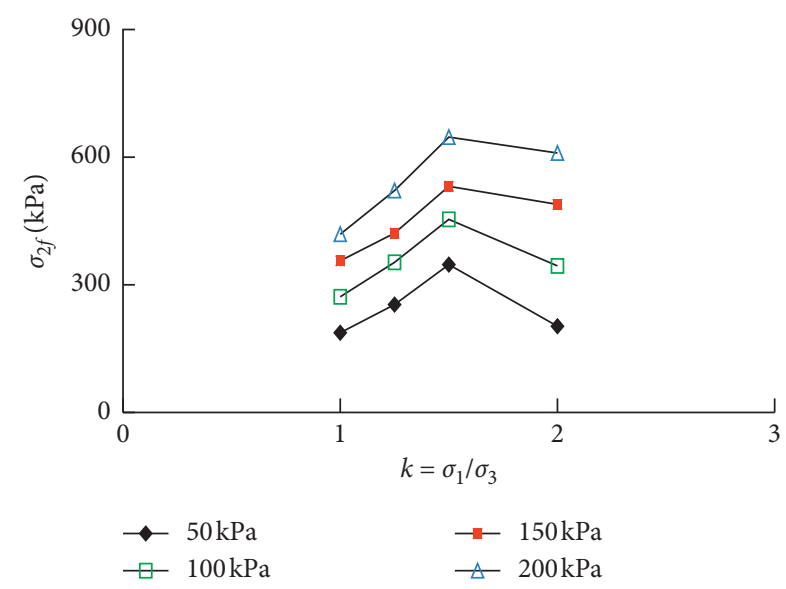

Figure 12: Change law between $\sigma_{2 f}$ and $k$ in a failure state.

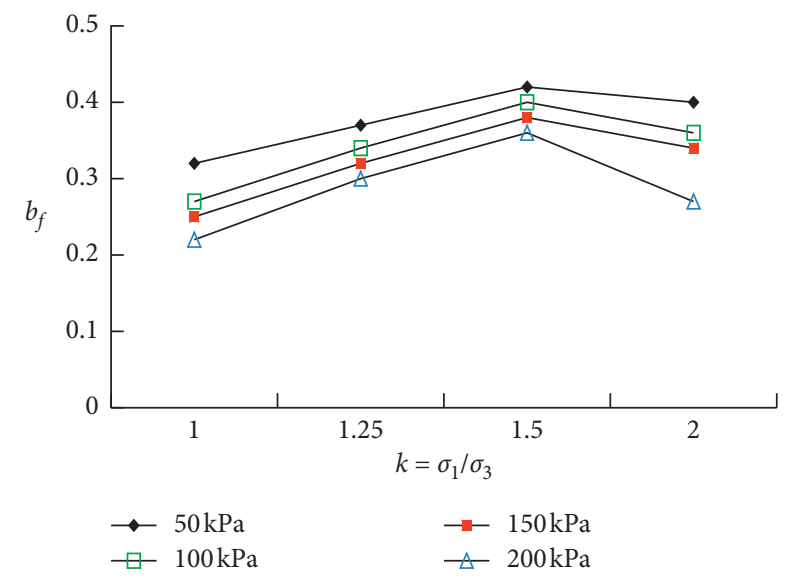

FIgURE 13: Change law between $b_{f}$ and $k$ in a failure state.

4.3. Analysis of Strength Characteristics. The relationship curves of $q_{f} \sim \sigma_{3 c}, q_{f} \sim p_{f}$, and $q_{f} \sim k$ are shown in Figures 15, 16, and 17, respectively.

Figures 15-17 show the increase of consolidation confining pressure and spherical stress. General shear stress is also increasing, which is approximately a linear

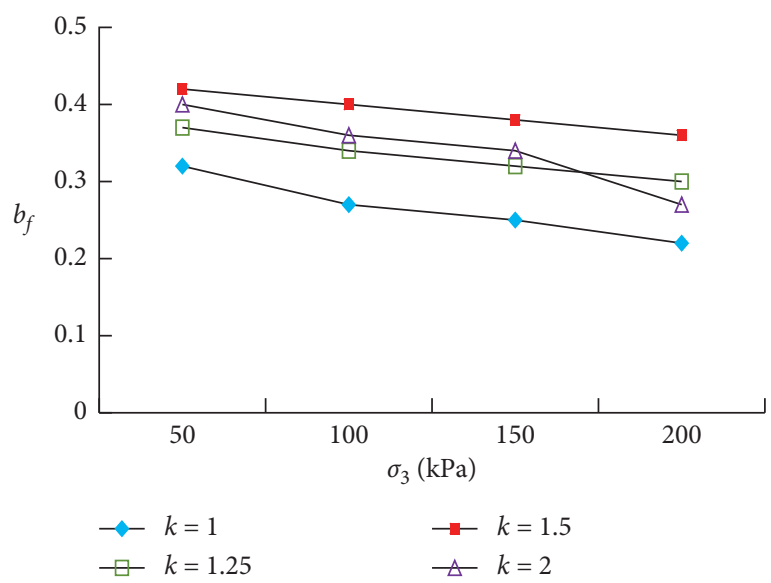

Figure 14: Change law between $b_{f}$ and $\sigma_{3}$ in a failure state.

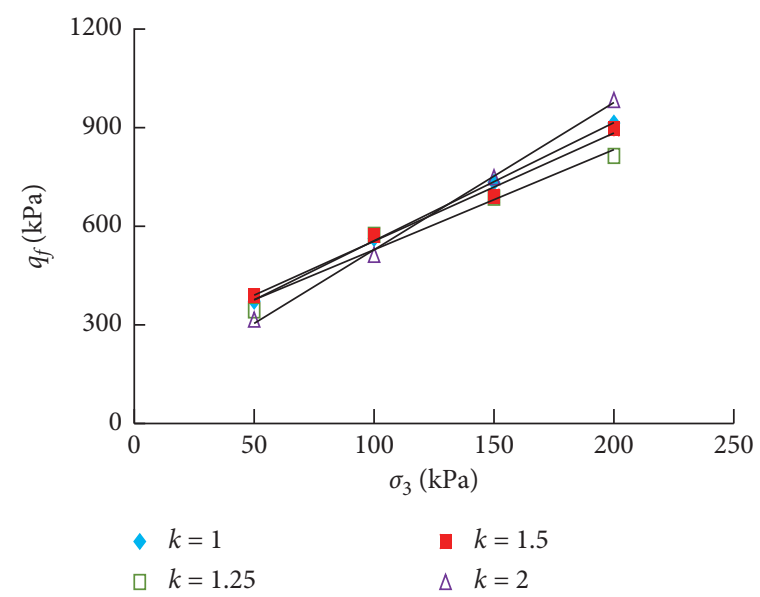

Figure 15: Change law between $q_{f}$ and $\sigma_{3 c}$.

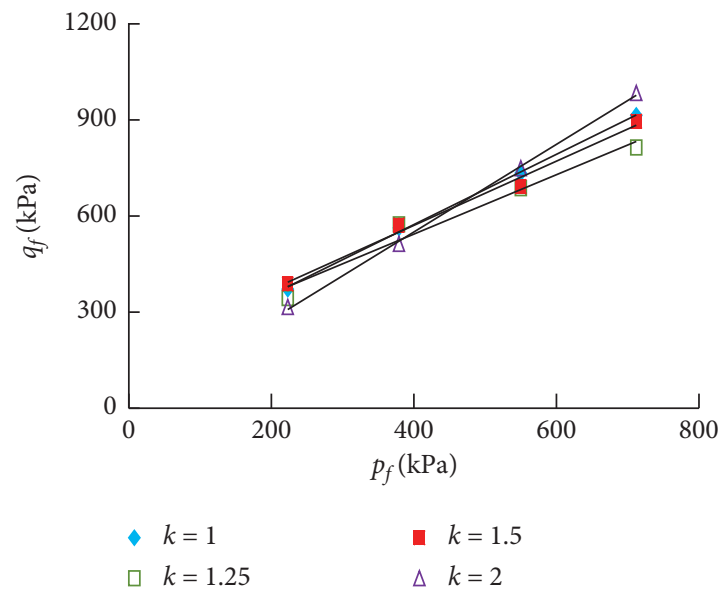

Figure 16: Change law between $q_{f}$ and $p_{f}$.

relationship. When the consolidation confining pressure is 50 and $100 \mathrm{kPa}$, the generalized shear stress decreases monotonously with the increase of $k$ value. When the confining pressure is 150 and $200 \mathrm{kPa}$, the general shear stress decreases first and then increases with the increase 


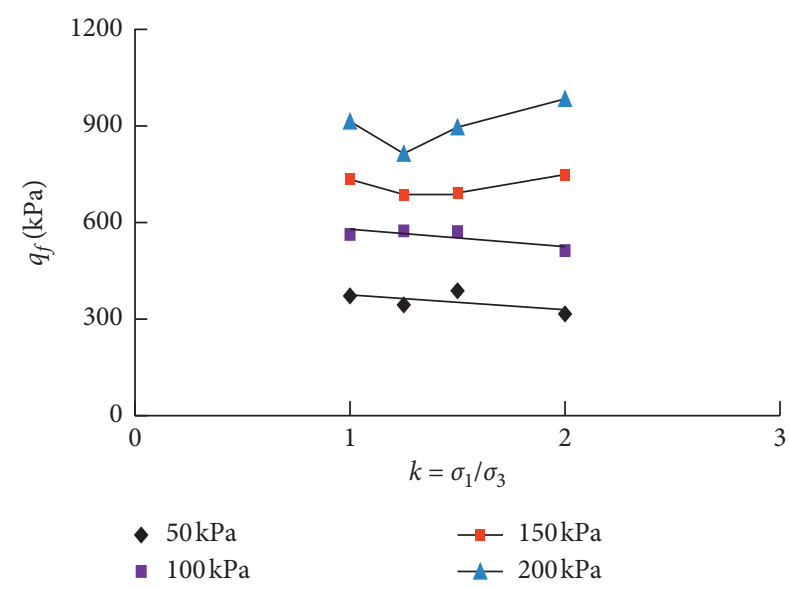

Figure 17: Change law between $q_{f}$ and $k$.

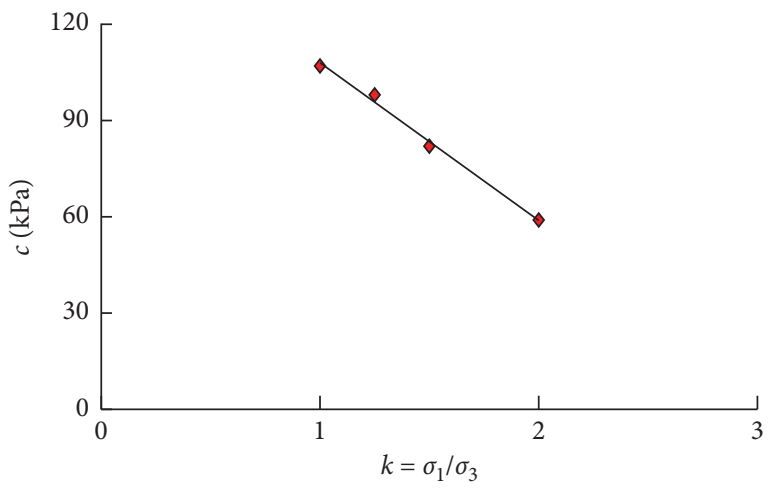

Figure 18: Change law between $c$ and $k$.

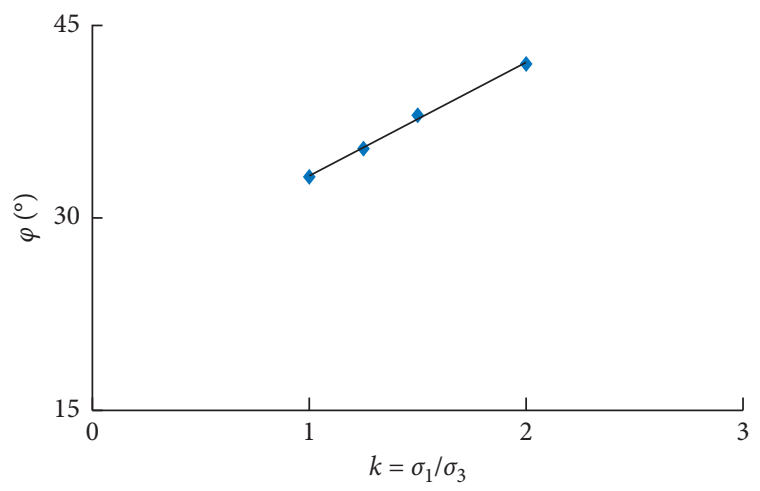

Figure 19: Change law between $\varphi$ and $k$.

in $k$ value. The experimental results further indicate that the influence of the initial stress state $k$ on the soil strength is closely related to the consolidation confining pressure. The bigger the $k$ value, the stronger the damage of the original soil structure under small confining pressure, which results in a decrease in soil strength. Given this condition, increasing the $k$ value helps the development of the loess vertical crack and weakens the adhesive force between the particles. The increase in confining pressure enhances lateral confinement. Therefore, the increase of $k$ value increases shear strength. Given this increase, the vertical cracked soil healing and strength of the secondary structure grow faster than the strength decrease caused by the original structure damage.

4.4. Analysis of Strength Parameters. According to the strength envelope under the plane strain state, cohesive force $c$ and internal friction angle $\varphi$ of the intact loess can be obtained under different $k$ values. The strength parameters changing with $k$ values are shown in Figures 18 and 19.

Figures 18 and 19 show that the cohesion force decreases with the increase of $k$ value; the linear relationship is approximate. The increase of $k$ value develops the loess vertical crack, which weakened bond properties between soil particles. Moreover, with the increase of $k$ value, the shear strength of soil depends on the frictional effect between soil particles. Therefore, the internal friction angle increases.

\section{Conclusions}

(1) The stress-strain curves of intact loess with different confining pressures and different $k$ values are all of hardening types under vertical loading conditions, and the stress-strain curves conform to the hyperbolic type. Consolidation confining pressure and $k$ values affect the soil strength characteristics. The effect of different initial stress states' loess strength is closely related to the magnitude of consolidation stress.

(2) The relationships between the lateral and vertical strains of the intact loess with different confining pressures and $k$ values are nonlinear. The increase of consolidation confining pressure limits the development of lateral deformation. The effect of different initial stress states' $k$ values on lateral deformation is significantly affected by consolidation confining pressure.

(3) The intact loess shows shear shrinkage characteristics during vertical shear loading under different initial stress states with strong regularity. The volume and vertical strains are nonlinear. The increase of consolidation confining pressure restricts the development of lateral deformation macroscopically, and the volume strain increases. With the increase of the initial stress states' $k$ value, the structure of soil undergoes a process from reinforcement to damage. The increase of the lateral expansion deformation distortion offsets some vertical deformation, showing that the larger the $k$ value, the smaller the volume deformation.

(4) The consolidation confining pressure and the initial stress state influence the intermediate principal stress factor in the failure. With the increase of consolidation confining pressure, the intermediate principal stress factor decreases gradually. With the increase of $k$ value, the intermediate principal stress factor increases first and then decreases, and the regularity is obvious. 
Under the plane strain condition, the intermediate principal stress factor $b_{f}$ of intact loess with different initial stress states is between 0.2 and 0.4 .

(5) Given the increase of consolidation confining pressure and spherical stress, the general shear stress at failure also increases. This relationship can be approximately described as linear. The test results further indicate that the influence of the initial stress state on soil strength is closely related to consolidation confining pressure. The cohesive force decreases with the increase of $k$ value, and the relationship is linear. With the increase of the initial stress states' $k$ value, the internal friction angle of the soil increases linearly.

\section{Data Availability}

The data used to support the findings of this study are included within the article and are available from the corresponding author upon request.

\section{Conflicts of Interest}

The authors declare that they have no conflicts of interest.

\section{Acknowledgments}

This work was supported by the National Natural Science Foundation of China (No. 11802218); Science and Technology Plan Project of Shaanxi Province (No. 2019JQ-432); Shaanxi Key Laboratory of Loess Mechanics and Engineering (No. LME201801); Natural Science Foundation of Shaanxi Provincial Department of Education (No. 20JK0670).

\section{References}

[1] Z.-D. Liu, Loess Mechanics and Engineering, pp. 1-5, Shaanxi Science and Technology Press, Xi'an, China, 1997.

[2] P. Sun, J. Peng, L. Chen, Q. Lu, and O. Igwe, "An experimental study of the mechanical characteristics of fractured loess in western China," Bulletin of Engineering Geology and the Environment, vol. 75, no. 4, pp. 1639-1647, 2016.

[3] R.-J. Li, J.-D. Liu, and R. Yan, "Characteristics of structural loess strength and preliminary framework for joint strength formula," Water Science and Engineering, vol. 7, no. 3, pp. 319-330, 2014.

[4] M. Jiang, F. Zhang, H. Hu, Y. Cui, and J. Peng, "Structural characterization of natural loess and remolded loess under triaxial tests," Engineering Geology, vol. 181, pp. 249-260, 2014.

[5] N. Charles, W. Wai, H. Sadeghi, and F. Jafarzadeh, "Compression and shear strength characteristics of compacted loess at high suctions," Canadian Geotechnical Journal, vol. 54, no. 5, pp. 690-699, 2016.

[6] W.-L. Xie, P. Li, S. K. Vanapalli, and J.-D. Wang, "Prediction of the wetting-induced collapse behaviour using the soil-water characteristic curve," Journal of Asian Earth Sciences, vol. 151, pp. 259-268, 2018.

[7] L. Xu and M. R. Coop, "Influence of structure on the behavior of a saturated clayey loess," Canadian Geotechnical Journal, vol. 53, no. 6, pp. 1026-1037, 2016.

[8] W. Fan, L.-S. Deng, and W.-N. Yuan, "Double parameter binary-medium model of fissured loess," Engineering Geology, vol. 14, no. 9, pp. 1-29, 2017.
[9] S. Shao, Q. Wang, and A.-Z. Luo, "True triaxial apparatus with rigid-flexible-flexible boundary and remolded loess testing," Journal of Testing and Evaluation, vol. 45, no. 11, pp. 807-817, 2017.

[10] S. Shao, S.-J. Shao, Y. Zhang, and C.-L. Chen, "Novel soil strength criterion compared with conventional criteria," Acta Geomaterials, vol. 7, pp. 1-16, 2017.

[11] G. Dondi, A. Simone, V. Vignali, and G. Manganelli, "Numerical and experimental study of granular mixes for asphalts," Powder Technology, vol. 232, pp. 31-40, 2012.

[12] T. Noda, B. Xu, and A. Akira, "Realization of uniform deformation of soil specimen under undrained plane strain condition based on soil-water coupled finite deformation analysis considering inertia forces," Soils and Foundations, vol. 53, no. 6, pp. 937-950, 2013.

[13] L. Ho and B. Fatahi, "Analytical solution for the two-dimensional plane strain consolidation of an unsaturated soil stratum subjected to time-dependent loading," Computers and Geotechnics, vol. 67, pp. 1-16, 2015.

[14] X. Lu, M. Huang, and J. Qian, "Prediction of plane strain undrained diffuse instability and strain localization with noncoaxial plasticity," Soils and Foundations, vol. 54, no. 6, pp. 1070-1080, 2014.

[15] L. Zhang, Y. Nakata, and U.-G. Kim, "Influence of relative density, particle shape, and stress path on the plane strain compression behavior of granular materials," Acta Geotechnica, vol. 9, pp. 241-255, 2014.

[16] C.-G. Zhagn, J.-H. Zhao, and W. Fan, "Critical filling height of embankment on soft ground based on the generalized SMP criterion," Chinese Journal of Geotechnical Engineering, vol. 39, no. 76, pp. 1251-1257, 2017.

[17] M. Satake, "Stress-deformation and strength characteristics of soil under three different principal stress (Discussion)," Proceedings of Japan Society of Civil Engineers, vol. 246, pp. 137-138, 1976.

[18] G.-X. Mei, H. Chen, and T.-H. Lu, "Reach on lateral stressstrain relation on side of foundation pit with lateral unloading," Chinese Journal of Geotechnical Engineering, vol. 29, no. 1, pp. 3108-3112, 2010.

[19] Y. Zhang and S.-J. Shao, "An analysis of vertical loading deformation and strength characteristics of loess under plain strain condition," China Civil Engineering Journal, vol. 49, no. 3, pp. 112-121, 2016.

[20] Y. Zhang, S.-J. Shao, and L.-Q. Wang, "Analysis and verification of soil strength criterion in plain strain state," Rock and Soil Mechanics, vol. 36, no. 9, pp. 2501-2509, 2015.

[21] Y. Zhang, S.-J. Shao, and L.-J. Wang, "An analysis of plain strain deformation and strength characteristics of loess with vertical structure," in Proceedings of the 6th Asia Pacific Conference On Unsaturated Soils, Guilin, China, October 2015. 